J. Dairy Sci. 92:4249-4261

doi:10.3168/jds.2008-1906

(c) American Dairy Science Association, 2009.

\title{
The effect of floor surface on dairy cow immune function and locomotion score ${ }^{1}$
}

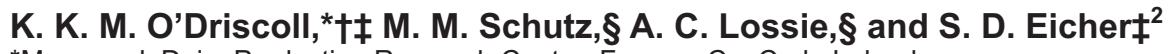 \\ *Moorepark Dairy Production Research Centre, Fermoy, Co. Cork, Ireland \\ †Department of Agriculture, Food Science and Veterinary Medicine, University College Dublin, Belfield, Dublin 4, Ireland \\ †USDA-ARS Livestock Behavior Research Unit, West Lafayette, IN 47907 \\ §Purdue University, West Lafayette, IN 47907
}

\section{ABSTRACT}

This study evaluated the effect of 2 dairy cow housing systems on cow locomotion, immune status, and expression of genes associated with lameness during the dry and periparturient periods. Cows were assigned to freestall housing with either rubber (RUB; $n=13$ ) or concrete $(\mathrm{CON} ; \mathrm{n}=14)$ at the feed-bunk and alley immediately after their first calving, and managed on this system during all subsequent lactations. At dry off, cows were moved to a straw bedded-pack dry cow pen, and remained there until about $2 \mathrm{~d}$ before subsequent calving. To investigate whether greater exposure to RUB or CON increased the differences between cows on each treatment, cows at the end of either their first (n $=16)$ or second $(\mathrm{n}=11)$ lactations were included in the experiment. Locomotion scores and blood samples were obtained at -60 (beginning of the dry period), -30 , 0 (after calving), +10 and +18 d relative to calving. Leukocyte counts were obtained by using an automated cell counter. Phagocytic activity, and cells positive for CD14 and CD18 expression were measured by flow cytometry using labeled microbeads and antibodies. Expression of tachikinin 1(TAC1), histamine receptor 1 (H1), and metalloproteinase (MMP)13 in blood leukocytes was estimated using quantitative real-time PCR. Treatment effects were determined using a repeated measures model. Provision of rubber flooring did not improve dairy cow locomotion during the subsequent study period. However, time relative to calving had an effect on locomotion score and speed, which were worst on d 0 , probably because of the discomfort associated with calving. An interaction occurred between treatment and time for neutrophil and lymphocyte counts. The RUB cows had greater neutrophil and lesser lympho-

Received November 17, 2008.

Accepted May 26, 2009.

${ }^{1}$ Mention of trade names or commercial products in this manuscript is solely for the purpose of providing specific information and does not imply recommendation or endorsement by the US Department of Agriculture.

${ }^{2}$ Corresponding author: Susan.Eicher@ars.usda.gov cyte numbers postpartum than CON. These cows also had more cells positive for CD14 postpartum compared with prepartum. Moreover, RUB cows showed upregulation of MMP13 and TAC1 compared with CON. These genes are associated with lameness and pain detection respectively. Greater neutrophil to lymphocyte ratios and CD14 expression are associated with physiological stress or with activated immunity. Rubber flooring is associated with an increase in activity and standing. This may have resulted in indications of physiological stress and upregulation of genes associated with lameness and pain for RUB cows. However, this study did not take into account the long-term effects of concrete or rubber flooring; for instance, occurrence of lameness or survivability within the herd.

Key words: floor surface, locomotion, dairy cow, immune function

\section{INTRODUCTION}

Freestall systems are frequently used to accommodate lactating dairy cows because they allow cows to be managed easily in groups and facilitate efficient feeding and cleaning (Stefanowska et al., 2001). Conventionally, freestalls are provided with bedding (e.g., sand, mats, and mattresses) with concrete underfoot at the feed bunk and in the alley ways. However, accommodating dairy cows on concrete flooring has been shown to be instrumental in the development of lameness (Cook et al., 2005; Vanegas et al., 2006); and it has been demonstrated as a risk factor for development of sole hemorrhages (Webster, 2001; Somers et al., 2003). Moreover, concrete flooring may not provide the friction necessary for cows to walk in a natural manner (van der Tol et al., 2005). Studies have shown that cows show a preference for standing and walking on soft flooring such as soft, textured rubber compared with concrete (Telezhenko et al., 2007) and will stand in bedded cubicles to obtain relief from concrete passageways (Boyle et al., 2007). This is important as lameness is considered one of the most serious welfare issues for dairy cows (Clarkson et al., 1996) and presents a significant cost to the dairy industry (Bicalho et al., 2008). 
Installation of rubber matting over concrete flooring may provide benefits for cow health and comfort. Cows accommodated in freestalls with rubber-covered alleys have been observed to spend more time standing on the rubber area than on concrete, indicating reduced discomfort while standing (Fregonesi et al., 2004; Boyle et al., 2007). In particular, rubber flooring at the feed area may have advantages for cows because cows can spend up to $25 \%$ of their time feeding and the majority of the remaining time lying down (Wierenga and Hopster, 1990; Fregonesi et al., 2004).

In addition, removal of cows from freestalls to accommodations that have a softer underfoot surface during the dry period may provide a recovery period for injured hooves. Accommodating dairy cows on woodchip out-wintering pads during their dry period has been shown to improve cow locomotion scores after calving compared with cows managed on concrete flooring (O'Driscoll et al., 2009). Furthermore, HernandezMendo et al. (2007) observed that a 4-wk rest period from concrete (by managing cows at pasture) improved locomotion scores of lactating cows.

Visual locomotion scoring systems are commonly used as indicators of the incidence and severity of lameness. However, disadvantages of this type of system include the time and labor involved, the subjectivity of the measure, and lack of sensitivity (O'Callaghan et al., 2003; O'Driscoll et al., 2009). Furthermore, cows do not consistently present behavioral expression of hoof or limb injury (impaired locomotion) until damage is advanced (Flower and Weary, 2006). Therefore, the development of objective measures that could indicate the onset of lameness is crucial.

Almeida et al. (2007) carried out a micro-arraybased gene expression profiling experiment using dairy cow peripheral blood mononuclear cells and reported upregulation of several genes associated with inflammation and pain in lame cows compared with sound cows. The study also found that lame dairy cows experience systemic changes consistent with immune system activation. These results indicate that there is potential for specific, lameness-associated biomarkers to be identified and for physiological changes to be integrated into lameness detection.

The transition period ( \pm 3 wk of calving) coincides with a period of immunosuppression for the dairy cow (Goff, 2008). The unavoidable changes in management and physiology of the cow during this period pose a significant challenge in terms of maintaining homeostasis. Multiple stressors are identified as instigating a greater behavioral and physiological response than single stressors (Cook et al., 2007). Thus, the added discomfort of an unyielding underfoot substrate (concrete) compared with a softer substrate (rubber) may result in an increased physiological reaction by the cow immediately postpartum. This experiment had 3 objectives: 1) to compare locomotion scores of transition dairy cows that were managed on either a rubber- or concrete-floored feed area during the preceding lactation and both on a straw bedded-pack during the dry period, 2) to compare the immune status (neutrophil and monocyte activation, phagocytic ability, and differential cell counts) of these cows, and 3) to investigate expression of 3 genes that may be associated with pain or lameness during the dry and transition periods. Our hypothesis was that cows exposed to concrete flooring at the feed area would have higher (worse) locomotion scores than cows with a rubber floor in this area, that these cows would have impaired immune function, and that they would show upregulation of the 3 investigated genes, compared with cows exposed to rubber flooring.

\section{MATERIALS AND METHODS}

\section{Animals and Experimental Design}

The Purdue University animal care and use committee approved all procedures carried out during this experiment. The experiment was carried out at the Purdue University Dairy Research and Education Center between October 2006 and April 2007. Cows were housed in rubber-matted freestalls, with either concrete (CON; $\mathrm{n}=14$ ) or rubber (RUB; $\mathrm{n}=13$ ) flooring in the feed bunk area, the alleyway to the feed bunk, and water areas. All cows in the herd were assigned randomly to either CON or RUB at their first calving. Every second heifer that calved was assigned to either CON or RUB, in order that the cohort of cows in each treatment was approximately the same age. For this study, 27 Holstein cows approaching second $(\mathrm{n}=16)$ or third $(\mathrm{n}=11)$ lactation were used.

The rubber flooring was $24 \mathrm{~mm}$ thick with a grip profile surface (Kraiburg Kura P, Agromatic, Fond du Lac, WI). A technical report (German Agricultural Society Test Centre for Agricultural Machinery; DLG Test Report 5405: http://www.dlg-test.de/pbdocs/5405_e.pdf; accessed June 30, 2009) reported a penetration depth of $3.5 \mathrm{~mm}$ of a steel foot at a force of $2,000 \mathrm{~N}$. This translates as 7.84 to $9.8 \mathrm{~mm}$ for cows weighing 454 to $568 \mathrm{~kg}$. Slip resistance was described as good at a speed of $20 \mathrm{~mm} / \mathrm{s}$ on both dry and wet surfaces.

The cows were dried off approximately $60 \mathrm{~d}$ before the expected calving date and were moved to a beddedpack barn (having flooring created from compacted straw and manure with straw added twice a week as bedding) where they were managed as one group. The bedded-pack barn, with north-south orientation, was closed on 3 sides, but the east side was open. Cows were 
Table 1. Locomotion scoring system

\begin{tabular}{lll}
\hline Characteristic & Score & Definition \\
\hline Spine curvature & 1 & Spine totally flat during locomotion \\
& 2 & Slight departure from the horizontal plane \\
& 3 & Spine curvature clearly visible \\
Tracking & 5 & Spine abnormally arched \\
& 1 & Spine could not be more arched \\
& 2 & Hind footprint overlaps, or more forward than front footprint \\
& 3 & Tind footprint partly overlaps front footprint, but is slightly behind \\
Head carriage & 5 & Hind footprint separated from front footprint up to approximately $30 \mathrm{~cm}$ \\
& 1 & Hind footprint separate from front by more than 30 cm \\
& 2 & Head stationary during locomotion \\
Abduction/adduction & 3 & Marked vertical movement during locomotion \\
& 4 & Severe vertical movement during locomotion \\
& 5 & Head drops almost to grazing level during each step \\
& 2 & Hind limbs move forward parallel to vertical midline of animal \\
& 3 & Slight deviation from midline of animal \\
& 4 & Hooves form a C shape in the air as they move forward \\
& 5 & C shape so defined as to be almost circular \\
& & Hooves circle completely in the air between each step \\
\hline
\end{tabular}

offered a balanced dry-cow ration fed ad libitum and delivered once daily to a fence-line feed bunk that ran along the open side of the barn. Cows had continuous access to nonfreezing waterers. Straw was added to the bedded pack twice weekly. Approximately $30 \mathrm{~d}$ prepartum the cows were moved to a similar close-up pen in a nearly identical building for closer observation for signs of calving. Approximately $1 \mathrm{~d}$ prepartum cows were moved to an individual maternity pen with sawdust over a rubber mat covering half the pen and concrete for the remainder, where they calved. Postpartum, animals remained in an individual pen for $4 \mathrm{~d}$ and then returned to a freestall quadrant of the same treatment (CON or RUB) in which they had been housed before drying off. Cows in both CON and RUB were fed a balanced ration fed ad libitum. Cows on both treatments were fed the same lactation diet until they were moved to the dry cow lot. They were fed a dry cow diet for the first $30 \mathrm{~d}$ and a close-up ration for the $30 \mathrm{~d}$ before calving.

\section{Animal Measurements and Samples}

All measures and samples were obtained from each animal at 5 sampling points: $60 \pm 8 \mathrm{~d}$ and $30 \pm 7 \mathrm{~d}$ before parturition ( $\mathrm{d}-60$ and $\mathrm{d}-30$, respectively), 3 $\pm 2 \mathrm{~d}$ after parturition (d 0), and $10 \pm 2$ and $18 \pm 4$ $\mathrm{d}$ postpartum ( $\mathrm{d}+10$ and $\mathrm{d}+18$, respectively). Two blood samples were collected via coccygeal venipuncture. One sample was collected into a tube containing acid citrate dextrose (ACD) as an anticoagulant, the other into a tube containing EDTA as an anticoagulant. The tube containing ACD was immediately placed on ice. Locomotion score was assessed using a scoring system modified from O'Callaghan et al. (2003; Table 1). Cows were released individually from a holding pen and walked freely along a rubber-covered concrete alley, where they were assessed over a fixed distance $(8.71 \mathrm{~m})$ that was marked using tape at each end of the alley. A single experienced observer scored the animals from the left-hand side, and the time taken to complete the distance was recorded using a stopwatch. All animals were acclimated to the system, as they had encountered the apparatus during a previous experiment. The BW of each animal was also recorded on each occasion.

\section{Laboratory Procedures and Analysis}

Differential blood counts were determined from the blood collected in EDTA using an automatic cell counter (Hemovat 950, HV02769, Drew Scientific Inc., Dallas, TX).

\section{Whole-Blood Flow Cytometry Assays}

Flow cytometric analysis was performed on a Beckman Coulter system (Epics XL-MCL, Beckman Coulter Inc., Fullerton, CA) equipped with a 488-nm argon laser for excitation, a 525-band pass filter for detection of fluorescein isothiocyanate (FITC) emissions, and a 575-band pass filter for detection of R-phycoerythrin (RPE) emission. Data were analyzed using System II software (Beckman Coulter Inc.). For each sample the optical features of 10,000 cells were acquired. Control samples were also analyzed, and consisted of wholeblood samples that had been incubated without any stimulus. Percentage fluorescence-positive events were recorded. Electronic gates were set according to the 
negative control included in each test defining less than $2 \%$ of the cells as positive.

\section{CD14 and CD18 Labeling}

Antibodies. Mouse anti-human CD18 LFA-1, $\beta$-chain, antibody labeled with FITC (DakoCytomation, Glostrup, Denmark) and mouse anti-human CD14 antibody labeled with RPE (DakoCytomation) were used to stain leukocyte suspensions and then isolated from whole blood. After addition of the labeled antibodies to the blood, antibodies that were bound to leukocytes and generating a green (FITC) or red (RPE) fluorescence signal were quantified.

Labeling. Five hundred microliters of whole blood from the ACD vacutainer tubes were aliquoted into a 5 -mL polypropylene tube. The tube was incubated in a shaking waterbath at $37^{\circ} \mathrm{C}$ for $1 \mathrm{~h}$, and then $50 \mu \mathrm{L}$ was removed and placed in a separate tube. This acted as an unstained control and allowed gating of autofluorescence. Ten microliters of each antibody (CD18-FITC and CD14-RPE) were added to the original tube; the tube was vortexed, and returned to the water bath for an additional $40 \mathrm{~min}$ (light protected). After incubation in the water bath, $50 \mu \mathrm{L}$ of antibody-treated blood was aliquoted to another tube. Red blood cells were lysed by hypotonic lysis in which $0.9 \mathrm{~mL}$ of cold sterile water was added to each tube for $45 \mathrm{~s}$, and then $100 \mu \mathrm{L}$ of $10 \times$ Hanks' Balanced Salt Solution (HBSS) was added to restore isotonicity. Cells were centrifuged at 1,800 $\times g$ for $5 \mathrm{~min}$ at $4^{\circ} \mathrm{C}$. The supernatant was discarded and the cells resuspended in $500 \mu \mathrm{L}$ of $1 \times$ HBSS for analysis.

\section{Microbead Phagocytosis}

In vitro phagocytic activity was determined using FluoSpheres carboxylate-modified microspheres $(1 \mu \mathrm{m}$; Invitrogen Corporation, Chicago, IL). The microspheres were labeled with RPE, and after addition to whole blood, microspheres ingested by phagocytes and generating a red fluorescence signal were quantified. Four hundred fifty microliters of whole blood were taken from blood collected into ACD vacutainer tubes, and incubated in a shaking waterbath for $60 \mathrm{~min}$ at $37^{\circ} \mathrm{C}$. After incubation, a $50-\mu \mathrm{L}$ aliquot serving as a control was taken from the sample and hypotonically lysed. The cell pellet was resuspended in $1 \mathrm{~mL}$ of $1 \times$ HBSS . Twelve and one-half microliters of the microspheres was added to the remaining sample and incubated for a further $40 \mathrm{~min}$ in a shaking waterbath at $37^{\circ} \mathrm{C}$. After incubation, a $50-\mu \mathrm{L}$ aliquot was removed, red blood cells were lysed as described previously, and then resuspended in $1 \times$ HBSS.

\section{RNA Extraction}

Extraction was performed on whole blood collected in ACD vacutainer tubes using QIAmp RNA Blood Mini Kit (Qiagen, Valencia, CA). Extracted RNA was analyzed for quantity and purity using 260 and $280 \mathrm{~nm}$ spectrophotometer readings (GeneQuant pro, Biochrom Ltd., Cambridge, UK). Samples were stored at $-80^{\circ} \mathrm{C}$.

\section{cDNA Synthesis}

All instruments and surfaces used were treated with RNase Zap (Ambion Inc.) before beginning reverse transcription. Relative amounts of sample were combined with RNase-free water in order that the concentration of RNA was $100 \mu \mathrm{L} / \mathrm{mL}$. Following this, reverse transcription was carried out using TaqMan Reverse Transcription Reagents (product no. N8080234; Applied Biosystems, Foster City, CA). The reagent mixture contained $10 \mu \mathrm{L}$ of TaqMan RT buffer, $22 \mu \mathrm{L}$ of magnesium chloride, $20 \mu \mathrm{L}$ of dNTP, $5 \mu \mathrm{L}$ of random hexamers, $2.5 \mu \mathrm{L}$ of Multiscribe reverse transcriptase, and $2 \mu \mathrm{L}$ of RNase inhibitor. Exactly $38.5 \mu \mathrm{L}$ of sample was added and then centrifuged briefly to remove air bubbles. Tubes were transferred to a thermal cycler (PCRexpress, serial no.13330; Hybaid Ltd., Basingstoke, UK), and run for $60 \mathrm{~min}$. On completion of reverse transcription, samples were stored at $-80^{\circ} \mathrm{C}$ until further analysis.

Primers and Probes. Primer and probe sequences for quantitative real time-PCR (qRT-PCR) were designed using Primer Express 1.1 software (Applied Biosystems) and synthesized by Applied Biosystems (Table 2). Probes were labeled with VIC fluorescent dye.

$\boldsymbol{R} \boldsymbol{T}$-PCR. A total of $5 \mu \mathrm{L}$ of template cDNA was used for RT-PCR for each gene. Each sample was combined with $4.5 \mu \mathrm{L}$ of forward and reverse primer, 3.25 $\mu \mathrm{L}$ of probe, $7.75 \mu \mathrm{L}$ of diethyl pyrocarbonate-treated water, and $25 \mu \mathrm{L}$ of Master Mix (TaqMan Universal PCR Master Mix, Applied Biosystems) for the control genes. Bovine 18S rRNA was selected as a control gene and used for normalization purposes. All qRT-PCR reactions were performed in duplicate using template from individual animals in each reaction. A relative standard curve was used as the qRT-PCR quantification method. The standard curve was constructed using the following dilutions of cDNA (in triplicate): 1 , $0.5,0.25,0.125,0.0625$, and 0.0315 . A single control sample was selected to be used as the template for the standard curve. Quantitative RT-PCR was performed and analyzed using ABI Prism 7000 sequence detection system (Applied Biosciences). 
Table 2. Primer and probe sequences used for real-time PCR to measure gene expression in white blood cells of dairy cows

\begin{tabular}{lllll}
\hline $\begin{array}{l}\text { Gene } \\
\text { name }\end{array}$ & $\begin{array}{l}\text { GenBank } \\
\text { accession no. }\end{array}$ & Forward primer $\left(5^{\prime} \rightarrow 3^{\prime}\right.$ end $)$ & Reverse primer $\left(3^{\prime} \rightarrow 5^{\prime}\right.$ end $)$ & Probe \\
\hline TAC-1 & NM174193 & GCCGTGGCAGTGATTTTTTT & CGTTGGCTCCGATTTCTTCT & TCTCCACTCAACTGTCTG \\
H1 & NM174083 & CCTCAAGTACCTGCGGTATCG & AGGCGGCTAGGATGGTGAT & CAAGACCCGAGCATC \\
MMP-13 & NM174389 & AGCCTTCAAGGTGTGGTCTGAT & AGCAGTGCCATTGTGAATTCTG & CCCCTCTGAATTTTA \\
\hline
\end{tabular}

${ }^{1}$ TAC-1 = tachikinin 1; H1 = histamine receptor 1 ; MMP-13 = metalloproteinase 13.

\section{Statistical Analysis}

Data were analyzed using SAS software (version 9.1.3, 1989; SAS Institute Inc., Cary, NC). The animal was considered the experimental unit. Data were tested for normality before analysis by examination of box and normal distribution plots.

Speed (number of seconds to complete the fixed distance) and the mean of the other 4 aspects of locomotion were statistically analyzed using the Mixed procedure. Body weight was used as a covariate in the analysis. The fixed effects were treatment, sampling point (time), lactation number (first or second), date, and all 2-way interactions with day used as a repeated measure.

Differential cell counts were analyzed using a similar model. However, sampling point, centered within the average for each sampling point, was also used as a covariate to account for variability within each sampling point relative to calving. When data were not normally distributed they were transformed using a log (base 10) transformation before analysis. Flow cytometry data were analyzed using a similar model. An arcsine transformation was used to transform CD18 percentage.

Relative gene expression was analyzed using a similar model to the differential cell counts and flow cytometry data, but with BW also included as a covariate.

Data presented in this paper show the nontransformed values of the data; however, all $P$-values were calculated using the transformed data where necessary. The most appropriate covariance structure for each model was determined using the Akaike information criterion. A Tukey-Kramer adjustment was used to account for multiple comparisons. Statistical differences were reported when $P$-values were $<0.05$. Tendencies toward significance $(0.05<P<0.1)$ are also reported. Data are presented as least squares mean \pm standard error.

\section{RESULTS}

\section{Locomotion Scores}

An interaction between treatment and day relative to calving for the variable speed $(P<0.001$; Figure 1$)$ was detected. Cows on the CON treatment were slower on d 0 than on $\mathrm{d}-30(P=0.05)$ and on $\mathrm{d}+10$ than on $\mathrm{d}$ $-60(P<0.01)$. They were also faster on $\mathrm{d}-60$ than on $\mathrm{d}+18(P=0.001)$, whereas there was no difference in speed over time for RUB cows. Moreover, on $\mathrm{d}-60$, CON cows tended to be faster than RUB cows $(P=$ 0.07). Speed and locomotion score (for all cows) varied with time $(P<0.001, P<0.001$ for both; Figure 1$)$. Overall, cows were slowest on $\mathrm{d} 0$. Cow speed was lower on $\mathrm{d} 0$ than on $\mathrm{d}-30(P=0.01)$ and $\mathrm{d}-60(P<0.05)$. Furthermore, on $\mathrm{d}+10$ cows were slower than on $\mathrm{d}-30$ $(P<0.05)$, and tended to be slower on $\mathrm{d}+18$ than on $\mathrm{d}-30(P=0.08)$. Likewise, mean locomotion score was greatest on $\mathrm{d} 0$. On this day, mean score was greater than on $\mathrm{d}-30(P=0.001)$, and $\mathrm{d}-60(P<0.05)$. Mean locomotion score on $\mathrm{d}-30$ was less than on $\mathrm{d}$ $+10(P<0.05)$ and tended to be less than on $\mathrm{d}+18(P$ $=0.06)$. There was no effect of treatment on either cow speed or average locomotion score.

Speed and mean locomotion score were affected by lactation number $(P<0.01$ for both). Cows entering the second lactation had a higher speed $(1.6 \pm 0.1 \mathrm{~m} / \mathrm{s})$ than cows entering the third lactation $(1.2 \pm 0.1 \mathrm{~m} / \mathrm{s}$; $P<0.001)$, and had lower average locomotion scores $(1.6 \pm 0.1)$ than third-lactation cows $(1.9 \pm 0.1 ; P$ $<0.01)$. There tended to be an interaction between treatment and lactation number for cow speed $(P=$ 0.07; Figure 2). No difference was detected in CON cows, whether they were entering the second or third lactation. However, cows on rubber were slower when entering the third lactation than entering the second lactation $(P<0$. 01).

\section{Differential Blood Cell Counts}

Although there tended to be an effect of time $x$ treatment on total leukocyte count $(P=0.1$; Table $3)$, there was no effect of treatment, time, or lactation number, or any other interactive effects, on total leukocyte counts $(P=0.1$; Table 3$)$.

With regard to neutrophil count, a tendency for an effect of time $(P=0.07$; Table 3$)$ was observed. Neutrophil count tended to be greater at $\mathrm{d}+10$ than at $\mathrm{d}$ $-30(P=0.06)$. Furthermore, in the RUB treatment, neutrophil count was greater at $\mathrm{d}+10$ than at $\mathrm{d} 0(P$ $<0.05)$. There was also an effect of time $\times$ lactation 

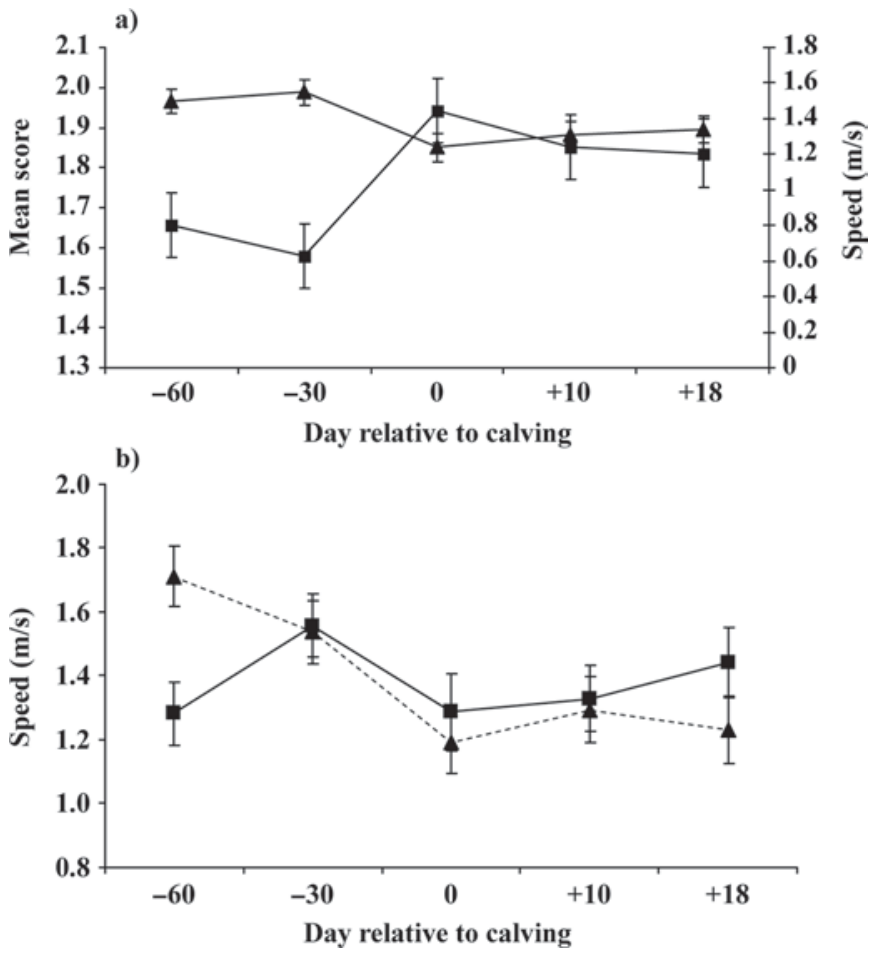

Figure 1. a) Cow speed $(\mathrm{m} / \mathrm{s} ;-\boldsymbol{\Lambda}-)$ and the average of the other 4 aspects of locomotion (spine curvature, tracking, head carriage, and ab/adduction, each scored from 1 to 5 , increasing with severity; - - ) on each recording occasion is represented; b) speed $(\mathrm{m} / \mathrm{s})$ of cows on concrete (--- $\left.\boldsymbol{\Delta}_{--}\right)$or rubber (- - $)$flooring, at each sampling point.

number $(P=0.01$; Figure 3$)$. Neutrophil count was greater in cows entering the second lactation than cows entering the third lactation at d 0. Furthermore, for cows entering the second lactation, neutrophil count on d 0 tended to be lesser than on $\mathrm{d}+10(P=0.06)$, and $\mathrm{d}+18(P=0.08)$. There were no differences between sampling points for cows entering the third lactation. There was no effect of treatment or lactation number on neutrophil count.

Although there was no effect of treatment or lactation number, time tended to have an effect on neutrophil percentage $(P=0.05$; Table 4$)$. Neutrophil percentage at $\mathrm{d}-30$ tended to be less than at $\mathrm{d}+10(P=0.08)$ and at $\mathrm{d}+18(P=0.1)$. Although there was no effect of treatment $\times$ time, within the RUB treatment, neutrophil percentage tended to be less at $\mathrm{d}-30$ than at $\mathrm{d}+10(P=0.1$; Table 4). Similar to neutrophil count, there was also an effect of time $\times$ lactation number $(P$ $=0.05)$ on neutrophil percentage. For cows entering the second lactation, neutrophil percentage tended to be greater at $\mathrm{d} 0$ than at $\mathrm{d}-30(P=0.1)$.

There was an effect of treatment $\times$ time on lymphocyte count $(P<0.05$; Table 3$)$, and although there was no significant difference, numerically lymphocyte count in the RUB treatment was lower postpartum than in the CON treatment. There were no other effects on lymphocyte count. Lymphocyte percentage tended $(P$ $=0.06$; Table 4) to have a treatment $\times$ time effect. Lactation number $\times$ time also tended $(P=0.09)$ to affect lymphocyte percentage.

Although time $(P=0.1$; Table 3$)$ tended to have an effect on monocyte count, no effect of treatment, lactation number, or interactive effects on monocyte count or percentage were seen.

A time effect was found for eosinophil count $(P<$ 0.05 ; Table 3$)$ and percentage of eosinophils $(P=0.001$; Table 4). Specifically, eosinophil count on $\mathrm{d}-30$ was greater than on $\mathrm{d}+18(P=0.01)$, and tended to be greater on $\mathrm{d}-60(P=0.1)$. Eosinophil percentage was greater on $\mathrm{d}-30$ than $\mathrm{d}+10(P=0.01)$ and on $\mathrm{d}$ $+18(P<0.001)$, and on $\mathrm{d}-60$ than on $\mathrm{d}+18(P=$ 0.05 ; Table 3$)$. Eosinophil percentage also tended to be greater on $\mathrm{d}-30$ than on $\mathrm{d} 0(P=0.1)$. There was no effect of treatment or lactation number on eosinophil count.

Time tended to affect neutrophil to lymphocyte ratio $(P=0.1$; Table 3$)$. A trend for a time $\times$ treatment interaction $(P=0.1$; Table 3$)$ and a time $\times$ lactation number $(P=0.06$; Figure 3$)$ were detected for neutrophil to lymphocyte ratio. On $\mathrm{d}+10$ the ratio for RUB cows tended to be greater than at $\mathrm{d}-30(P=$ 0.07 ), whereas for CON cows the ratio was similar at all sampling points. There was no effect of treatment or lactation number on neutrophil to lymphocyte ratio.

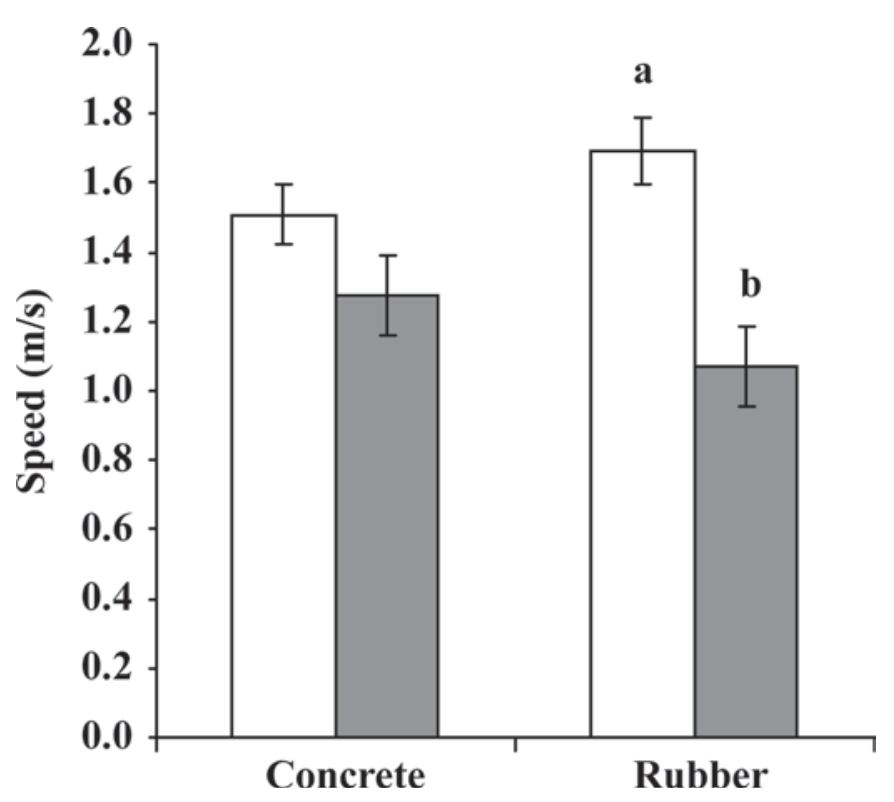

Figure 2. Speed $(\mathrm{m} / \mathrm{s})$ of cows in each treatment, entering either the second (white bar) or third (gray bar) lactation. Letters indicate a significant difference at $P<0.01$. 
Table 3. Effect of time relative to calving, treatment (concrete vs. rubber flooring), and their interactions on differential leukocyte cell counts (LSM \pm SE)

\begin{tabular}{|c|c|c|c|c|c|c|c|c|c|}
\hline \multirow[b]{2}{*}{ Blood parameter } & \multirow[b]{2}{*}{ Treatment } & \multicolumn{5}{|c|}{ Time relative to calving ${ }^{1}$} & \multicolumn{3}{|c|}{$P$-value } \\
\hline & & $\mathrm{d}-60$ & $\mathrm{~d}-30$ & d 0 & $\mathrm{~d}+10$ & $\mathrm{~d}+18$ & Time & Treatment & Time $\times$ Treatment \\
\hline \multirow[t]{2}{*}{$\mathrm{WBC}^{2}\left(\times 10^{9} / \mathrm{L}\right)$} & Concrete & $10.0 \pm 1.0$ & $9.2 \pm 1.0$ & $11.0 \pm 1.0$ & $10.0 \pm 1.0$ & $9.8 \pm 1.0$ & 0.29 & 0.98 & 0.13 \\
\hline & Rubber & $10.4 \pm 1.1$ & $9.4 \pm 1.1$ & $8.9 \pm 1.1$ & $11.6 \pm 1.1$ & $9.8 \pm 1.1$ & & & \\
\hline \multirow[t]{2}{*}{ Neutrophils $(\mathrm{N})\left(\times 10^{9} / \mathrm{L}\right)^{3}$} & Concrete & $4.1 \pm 0.6$ & $3.6 \pm 0.6$ & $4.9 \pm 0.6$ & $4.5 \pm 0.6$ & $4.3 \pm 0.6$ & 0.07 & 0.49 & 0.04 \\
\hline & Rubber & $4.5 \pm 0.6$ & $3.7 \pm 0.6$ & $3.8 \pm 0.6$ & $6.2 \pm 0.6$ & $4.9 \pm 0.7$ & & & \\
\hline \multirow[t]{2}{*}{ Lymphocytes $(\mathrm{L})\left(\times 10^{9} / \mathrm{L}\right)$} & Concrete & $5.3 \pm 0.6$ & $4.9 \pm 0.6$ & $5.3 \pm 0.6$ & $5.3 \pm 0.6$ & $5.2 \pm 0.6$ & 0.16 & 0.72 & 0.03 \\
\hline & Rubber & $5.2 \pm 0.7$ & $5.1 \pm 0.7$ & $4.4 \pm 0.7$ & $4.7 \pm 0.7$ & $4.5 \pm 0.7$ & & & \\
\hline \multirow[t]{2}{*}{ Monocytes $\left(\times 10^{9} / \mathrm{L}\right)$} & Concrete & $0.33 \pm 0.04$ & $0.30 \pm 0.04$ & $0.32 \pm 0.04$ & $0.25 \pm 0.04$ & $0.31 \pm 0.04$ & 0.1 & 0.80 & 0.89 \\
\hline & Rubber & $0.37 \pm 0.04$ & $0.27 \pm 0.04$ & $0.28 \pm 0.04$ & $0.24 \pm 0.04$ & $0.30 \pm 0.05$ & & & \\
\hline \multirow[t]{2}{*}{ Eosinophils $\left(\times 10^{9} / \mathrm{L}\right)$} & Concrete & $0.27 \pm 0.06$ & $0.35 \pm 0.05$ & $0.20 \pm 0.05$ & $0.15 \pm 0.05$ & $0.13 \pm 0.06$ & 0.04 & 0.90 & 0.89 \\
\hline & Rubber & $0.25 \pm 0.07$ & $0.29 \pm 0.06$ & $0.21 \pm 0.06$ & $0.23 \pm 0.06$ & $0.15 \pm 0.06$ & & & \\
\hline \multirow[t]{2}{*}{$\mathrm{N} / \mathrm{L}$ ratio } & Concrete & $0.87 \pm 0.20$ & $0.92 \pm 0.20$ & $1.08 \pm 0.20$ & $1.00 \pm 0.20$ & $0.97 \pm 0.20$ & 0.1 & 0.5 & 0.1 \\
\hline & Rubber & $0.98 \pm 0.22$ & $0.83 \pm 0.22$ & $0.89 \pm 0.22$ & $1.63 \pm 0.22$ & $1.36 \pm 0.23$ & & & \\
\hline
\end{tabular}

${ }^{1}$ Number of days relative to calving for $\mathrm{d}-60, \mathrm{~d}-30, \mathrm{~d} 0, \mathrm{~d}+10$, and $\mathrm{d}+18$ were $-60 \pm 8,-30 \pm 7,3 \pm 2,10 \pm 2$, and $18 \pm 4 \mathrm{~d}$, respectively.

${ }^{2} \mathrm{WBC}=$ white blood cells.

${ }^{3}$ Indicates model run with nontransformed data.

Table 4. Effect of time relative to calving, treatment (concrete vs. rubber flooring), and their interactions on differential leukocyte cell percentages (LSM \pm SE)

\begin{tabular}{|c|c|c|c|c|c|c|c|c|c|}
\hline Blood parameter & Treatment & $d-60$ & $\mathrm{~d}-30$ & d 0 & $\mathrm{~d}+10$ & $\mathrm{~d}+18$ & Time & Treatment & Time $\times$ Treatment \\
\hline Neutrophil (\%) & $\begin{array}{l}\text { Concrete } \\
\text { Rubber }\end{array}$ & $\begin{array}{l}42.1 \pm 2.9 \\
44.3 \pm 3.1\end{array}$ & $\begin{array}{l}41.6 \pm 2.9 \\
41.3 \pm 3.1\end{array}$ & $\begin{array}{l}45.7 \pm 2.9 \\
42.7 \pm 3.1\end{array}$ & $\begin{array}{l}43.6 \pm 2.9 \\
50.5 \pm 3.1\end{array}$ & $\begin{array}{l}44.8 \pm 3.0 \\
49.5 \pm 3.3\end{array}$ & 0.05 & 0.53 & 0.16 \\
\hline Lymphocyte (\%) & Concrete & $50.9 \pm 3.0$ & $50.8 \pm 3.0$ & $49.5 \pm 3.0$ & $52.3 \pm 3.0$ & $\begin{array}{l}49.0 \pm 0.0 \\
50.7 \pm 3.1\end{array}$ & & & \\
\hline & Rubber & $49.1 \pm 3.2$ & $52.7 \pm 3.2$ & $51.6 \pm 3.2$ & $43.9 \pm 3.2$ & $45.8 \pm 3.3$ & 0.41 & 0.47 & 0.06 \\
\hline Monocyte (\%) & $\begin{array}{l}\text { Concrete } \\
\text { Rubber }\end{array}$ & $\begin{array}{l}3.3 \pm 0.4 \\
3.0 \pm 0.5\end{array}$ & $\begin{array}{l}3.1 \pm 0.4 \\
2.3 \pm 0.5\end{array}$ & $\begin{array}{l}2.9 \pm 0.4 \\
3.0 \pm 0.5\end{array}$ & $\begin{array}{l}2.6 \pm 0.5 \\
3.4 \pm 0.5\end{array}$ & $\begin{array}{l}3.2 \pm 0.5 \\
3.1 \pm 0.5\end{array}$ & 0.91 & 0.77 & 0.48 \\
\hline Eosinophil (\%) & $\begin{array}{l}\text { Concrete } \\
\text { Rubber }\end{array}$ & $\begin{array}{l}3.0 \pm 0.6^{\text {ab }} \\
2.2 \pm 0.7\end{array}$ & $\begin{array}{l}4.1 \pm 0.5^{\mathrm{b}} \\
3.0 \pm 0.6\end{array}$ & $\begin{array}{l}1.8 \pm 0.5^{\mathrm{ab}} \\
2.4 \pm 0.6\end{array}$ & $\begin{array}{l}1.3 \pm 0.6^{\mathrm{a}} \\
1.8 \pm 0.6\end{array}$ & $\begin{array}{l}1.3 \pm 0.6^{\mathrm{a}} \\
1.5 \pm 0.6\end{array}$ & 0.001 & 0.99 & 0.71 \\
\hline
\end{tabular}

$\lesssim \quad{ }^{a, b}$ Within row, means with different superscripts are significantly different $(P<0.05)$.

${ }^{1}$ Number of days relative to calving for $\mathrm{d}-60, \mathrm{~d}-30, \mathrm{~d} 0, \mathrm{~d}+10$, and $\mathrm{d}+18$ were $-60 \pm 8,-30 \pm 7,3 \pm 2,10 \pm 2$, and $18 \pm 4 \mathrm{~d}$, respectively. 


\section{Microbead Phagocytosis, Monocyte and Neutrophil Differentiation}

There was no effect of treatment (RUB $=58.7 \pm$ $3.1 \%, \mathrm{CON}=60.3 \pm 2.5 \%$ ), lactation number or time $\times$ treatment interaction on the proportion of cells that tested positive for microbead phagocytosis. However, there tended to be an effect of time $(P=0.1$; Table 5$)$

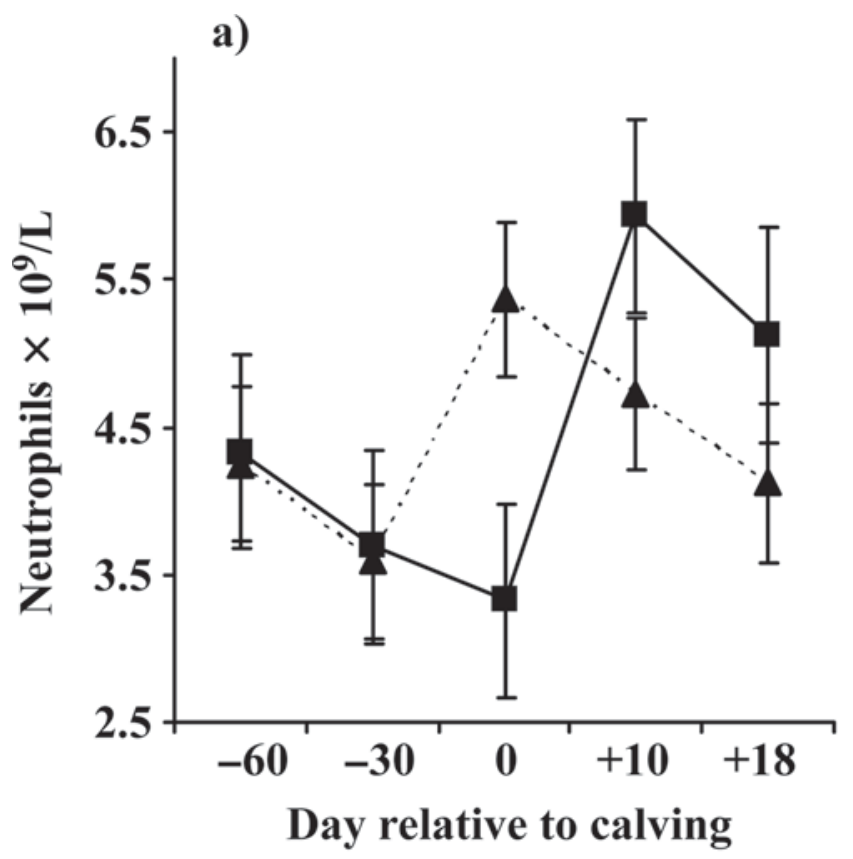

b)

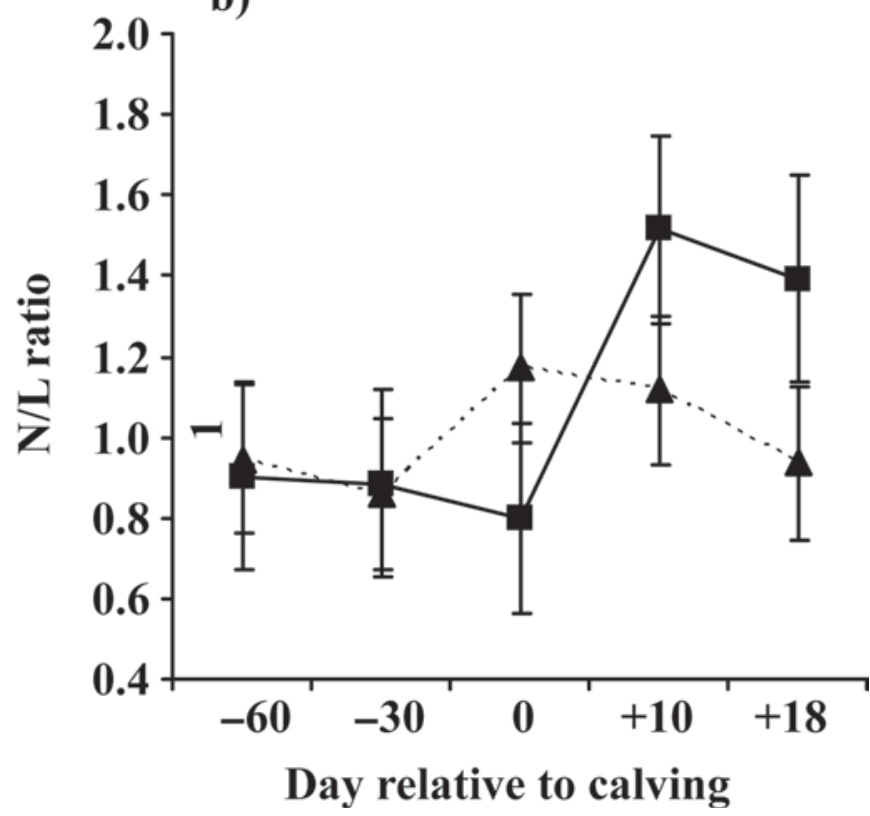

Figure 3. a) Neutrophil count $(P<0.01)$ and b) neutrophil to lymphocyte $(\mathrm{N} / \mathrm{L})$ ratio $(P<0.06)$ at each sampling point for cows entering their second (--- $\mathbf{\Delta - -})$ or third (- - $)$ lactation. and there was a time $\times$ lactation number interaction $(P<0.05)$.

There was no effect of treatment on the percentage of cells that tested positive for CD14 (RUB $=30.0 \pm$ $2.8 \%, \mathrm{CON}=27.8 \pm 2.5 \%)$. However, there was an effect of time $(P<0.01$; Table 5$)$. Although there was no time by treatment interaction, the percentage of cells positive for CD14 in the RUB treatment was greater at d 0 and $\mathrm{d}+10$ than at $\mathrm{d}-30(P<0.01$ and $P<0.05$ respectively; Figure 4), whereas there was no difference between CD14 percentages at any sampling point for cows in the CON treatment.

No effect of treatment, time, lactation, or their interactions was detected on percentage of cells that tested positive for CD18 (Table 5; Figure 4). However, although there was no difference within either treatment between sampling points, cows in the RUB treatment had a numerical increase in percentage of positive cells at $\mathrm{d} 0$, whereas cows in the CON treatment did not.

\section{qRT-PCR}

An interaction of time $\times$ lactation number $(P<$ 0.05) was observed in expression of histamine receptor 1 (H1) mRNA, although there were no differences between lactation numbers at any sampling point. There was no effect of treatment, time, or lactation number on relative expression of $\mathrm{H} 1 \mathrm{mRNA}$ (Figures 5 and 6). Expression of tachikinin-1 (TAC-1) tended to be greater for cows in RUB $(P<0.07$; Figure 5$)$. Sampling point also tended to have an effect on TAC-1 expression $(P=0.09)$. Expression was greater at $\mathrm{d}-60$ than at $\mathrm{d}$ $0(P<0.05)$ overall, and tended to be greater at these sampling points in the RUB treatment $(P=0.1$; Figure 6). Expression of metalloproteinase (MMP) 13 was greater for RUB cows $(P<0.02$; Figure 5$)$. However, there were no other effects.

\section{DISCUSSION}

Previous studies comparing the effects of rubber and concrete flooring on dairy cow health and welfare have focused on hoof health and behavior (e.g., Vanegas et al., 2006; Boyle et al., 2007; Haufe et al., 2008). This is the first study to our knowledge that has used measures of behavior (locomotion scoring), immune status (leukocyte counts, phagocytic activity, and CD14 and CD18 proliferation) and gene expression concurrently. Moreover, this study used animals that had been managed solely on either rubber or concrete flooring for their entire productive lives, which is reflective of an on-farm situation. Thus, these results are an important contribution to the present understanding of the relationship of floor surface with well being. 
Table 5. Effect of time relative to calving on the percentage of cells positive for CD14, CD18, and microbead phagocytosis $(\mathrm{LSM} \pm \mathrm{SE})$

\begin{tabular}{lcccccc}
\hline & \multicolumn{5}{c}{ Time relative to calving } \\
\cline { 2 - 5 } Phagocytosis & $\mathrm{d}-60$ & $\mathrm{~d}-30$ & $\mathrm{~d} 0$ & $\mathrm{~d}+10$ & $\mathrm{~d}+18$ & $P$-value for time \\
\hline CD14 & $26.4 \pm 3.8$ & $22.2 \pm 2.8$ & $33.2 \pm 2.5$ & $32.3 \pm 2.7$ & $30.5 \pm 2.8$ & 0.01 \\
CD18 & $90.4 \pm 4.2$ & $82.2 \pm 3.3$ & $85.7 \pm 3.0$ & $84.3 \pm 3.1$ & $80.7 \pm 3.2$ & 0.65 \\
Microbeads & $67.0 \pm 5.1$ & $55.5 \pm 3.6$ & $59.2 \pm 3.2$ & $54.7 \pm 3.3$ & $61.2 \pm 3.5$ & 0.10
\end{tabular}

${ }^{1}$ Number of days relative to calving for $\mathrm{d}-60, \mathrm{~d}-30, \mathrm{~d} 0, \mathrm{~d}+10$, and $\mathrm{d}+18$ were $-60 \pm 8,-30 \pm 7,3 \pm 2$, $10 \pm 2$, and $18 \pm 4 \mathrm{~d}$, respectively.

Overall, there was a similar pattern over time with regard to locomotion score and speed. Higher values for locomotion scores and lower values for cow speed indicate poorer mobility. Thus for both measures, cows had worst locomotion at $\mathrm{d} 0$, probably because they were still recovering from the discomfort and physical effects of calving. However, it is important to note that, in general, cow locomotion in both treatments was good, and none of the cows were classified as clinically lame.

Cows entering the second lactation had better locomotion than cows entering the third, which is in agreement with the literature (Offer et al., 2000; O'Driscoll et al., 2009). In particular, for cows in the third lactation, animals in the rubber treatment had worse locomotion scores. O'Driscoll et al. (2008) found that cows managed on a soft surface (woodchip) during the dry period had softer hooves than cows managed on a hard surface (concrete). Soft hooves could be more susceptible to damage and may not protect the internal tissue of the hoof as much as hard hoof horn (Borderas et al., 2004). It is possible that the rubber flooring in this study had a similar effect, and that this may have had more of a detrimental effect than concrete on cow locomotion as cows aged.

Besides neutrophil count, differential cell counts were within normal ranges for cattle (Radostits et al., 2007). Indeed, total leukocyte counts were similar to those reported at comparable sampling points by Kulberg et al. (2002). Neutrophil count was slightly above the normal range of 0.6 to $4.0 \times 10^{9}$ cells/L, in particular at the postpartum sampling points. Around the time of parturition cows experience neutrophilia as a response to a surge in glucocorticoids (Kulberg et al., 2002; Burton et al., 2005), which explains this increase. The numerical decrease in lymphocyte and eosinophil count at parturition is also in agreement with reports in the literature (Kulberg et al., 2002). The increase in neutrophil count postpartum, however, was only significant in cows on rubber, and not cows managed on concrete flooring. Buckham-Sporer et al. (2008) found that bulls subjected to transportation stress had elevated total leukocyte counts at the onset of stress, and that this was correlated with a concurrent increase in neutrophil count. Thus, it is possible that the increase in neutrophil count postpartum was greater in cows on rubber because returning to this underfoot substrate postpartum was more stressful than a return to more unyielding concrete flooring. This is opposite to what we expected, but is somewhat in agreement with the increase in locomotion score that occurred in older cows on rubber flooring, as opposed to cows on concrete.

Traditionally, assessment of physiological stress has been estimated by measuring levels of adrenal hormones. However, there are associated drawbacks, such as the potential for rapid changes in hormone levels as a response to short-term acute stressors. Thus, an alternative method of assessing physical stress that has potential to reflect a more chronic state for the animal is investigation of relative white blood cell counts (Davis et al., 2008). Physiological stress causes a concurrent rise in neutrophil (N) number, and drop in lymphocyte $(\mathbf{L})$ number, and thus a composite measure that is often used to assess the stress response is the N:L ratio (Davis et al., 2008). An increase in N:L ratio at parturition has previously been reported in dairy cows (Kulberg et al., 2002) and is probably caused by the surge in cortisol at parturition (Burton et al., 2005). Moreover, a high N:L ratio has also been described in animals in stressful circumstances (Fell et al., 1999; Blanco et al., 2008) and in cows that are genetically more susceptible to disease (Kulberg et al., 2002). The tendency for $\mathrm{N}: \mathrm{L}$ ratio in cows on rubber to be higher postpartum arises from the high neutrophil counts and low lymphocyte counts recorded in this treatment at this sampling point compared with cows in the concrete treatment.

An increase in circulating neutrophil counts as a response to glucocorticoids is thought to occur because neutrophils are less able to migrate to the site of infection, and have increased longevity in blood (Kulberg et al., 2002; Burton et al., 2005). There are also indications that they have decreased antimicrobial functionality (Burton et al., 2005). Cell membrane CD14 is mostly found on the surface of monocytes and macrophages 

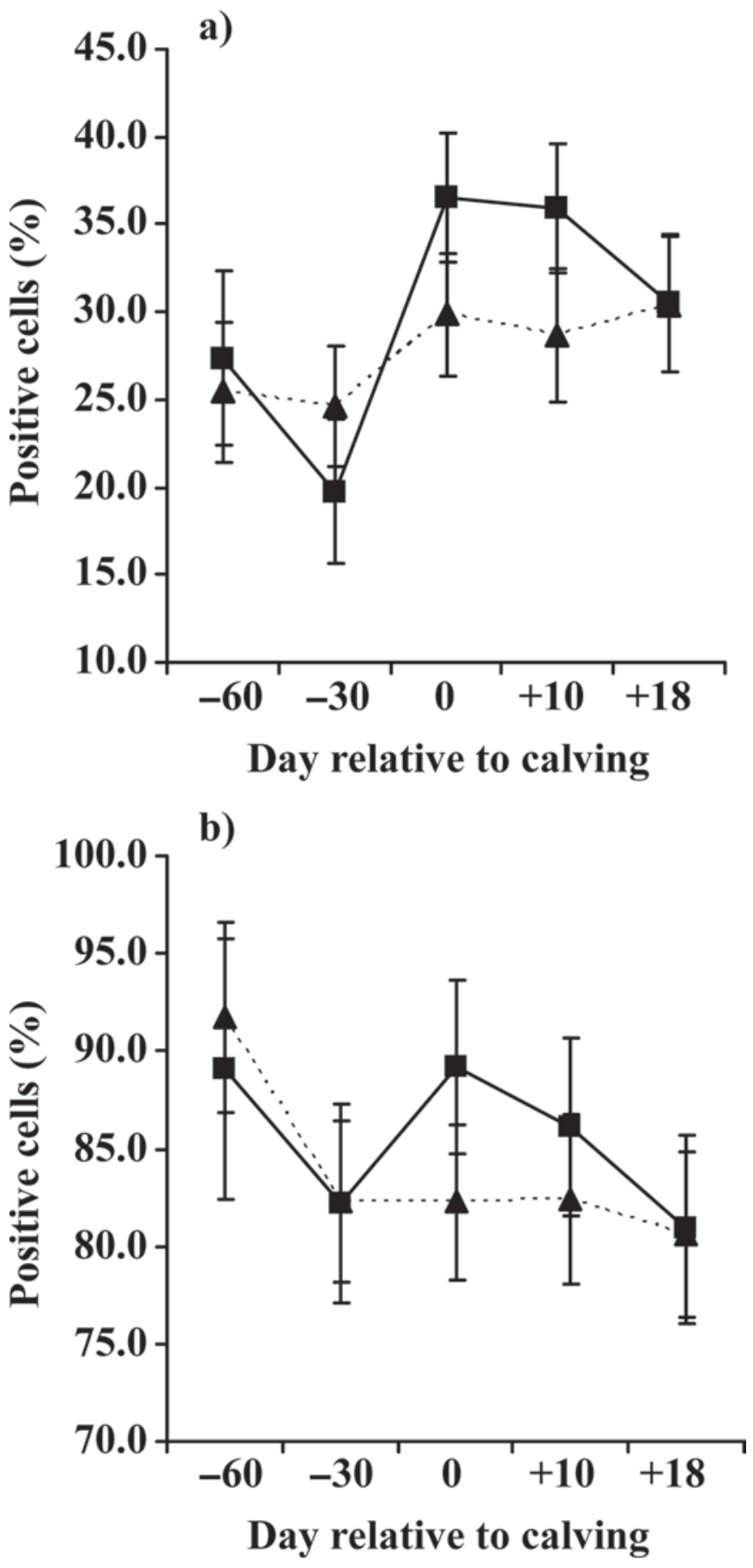

Figure 4. a) Percentage of cells positive for CD14 and b) percentage of cells positive for CD18 in either concrete (--- $\mathbf{\Delta - - - )}$ or rubber (一-) floor treatments.

(Troelstra et al., 1997) and is involved in recognizing gram-negative bacteria, whereas CD18 is found on the neutrophil cell surface and is involved in cell migration toward a site of infection (Yagi et al., 2004). Increased expression of cell membrane CD14 is often used as an indicator of monocyte activation, as it occurs in response to lipopolysaccharide, which is a major component of the outer membrane of gram-negative bacteria (Kawabata et al., 2002). However, it is also associated with a response to physiological or psychological stress in rats, humans, and calves (Kawabata et al., 2002; Reber et al., 2008). Moreover, Reber et al. (2008) found that calves that were not fed maternal colostrum had a greater cell surface density of CD14 than calves fed colostrum and concluded that this may be an indicator of stress. Williams et al. (2008) found that lower CD14 expression in rested compared with nonrested pigs was indicative that those animals that had a rest period during transport were better able to establish a mature population of macrophages. Thus, it is possible that the higher expression of CD14 at calving and postpartum in cows on rubber is an indication that these animals were under more physiological stress than cows on concrete. The phagocytosis and CD18 fluorescence show the phagocytotic ability and neutrophils of both treatments were similarly activated throughout the study.

The matrix metalloproteinases are a family of enzymes that are responsible for connective tissue catabolism (Parsons et al., 1997). In particular, MMP-13 is involved in the pathogenesis of arthritic diseases. Almeida et al. (2007) found that MMP-13 mRNA is more highly expressed in peripheral blood mononuclear cells of lame cows than sound cows and concluded that this gene may be a suitable biomarker for detection of lameness. The gene TAC- 1 is a precursor gene for substance $\mathrm{P}$, a neuropeptide that is involved in pain perception. Substance P is related to limb pain in horses (de Grauw et al., 2006), but we are not aware of any literature that has investigated expression of genes associated with substance $\mathrm{P}$ and cattle lameness or limb discomfort. The upregulation of TAC-1 in cows on rubber suggests that these cows may experience more discomfort or pain than cows on concrete. The upregulation of MMP-13 and TAC-1 in cows that were managed on rubber is in agreement with the immunological results. Thus, it is possible that cows experience more of a systemic inflammatory response when managed on a rubber floor compared with a concrete floor.

Previous studies comparing rubber and concrete flooring conclude that rubber probably provides, at least in the short-term, physical relief for cows. When only provided with concrete, cows spend more time standing in cubicles (Boyle et al., 2007; Haufe et al., 2008) than when provided with rubber. They also have a preference for walking on rubber over concrete (Platz et al., 2008). However, Fregonesi et al. (2004) found that cows on rubber flooring spent more time standing and less lying than cows on concrete, potentially as a result of decreased immediate physical discomfort. Moreover, 


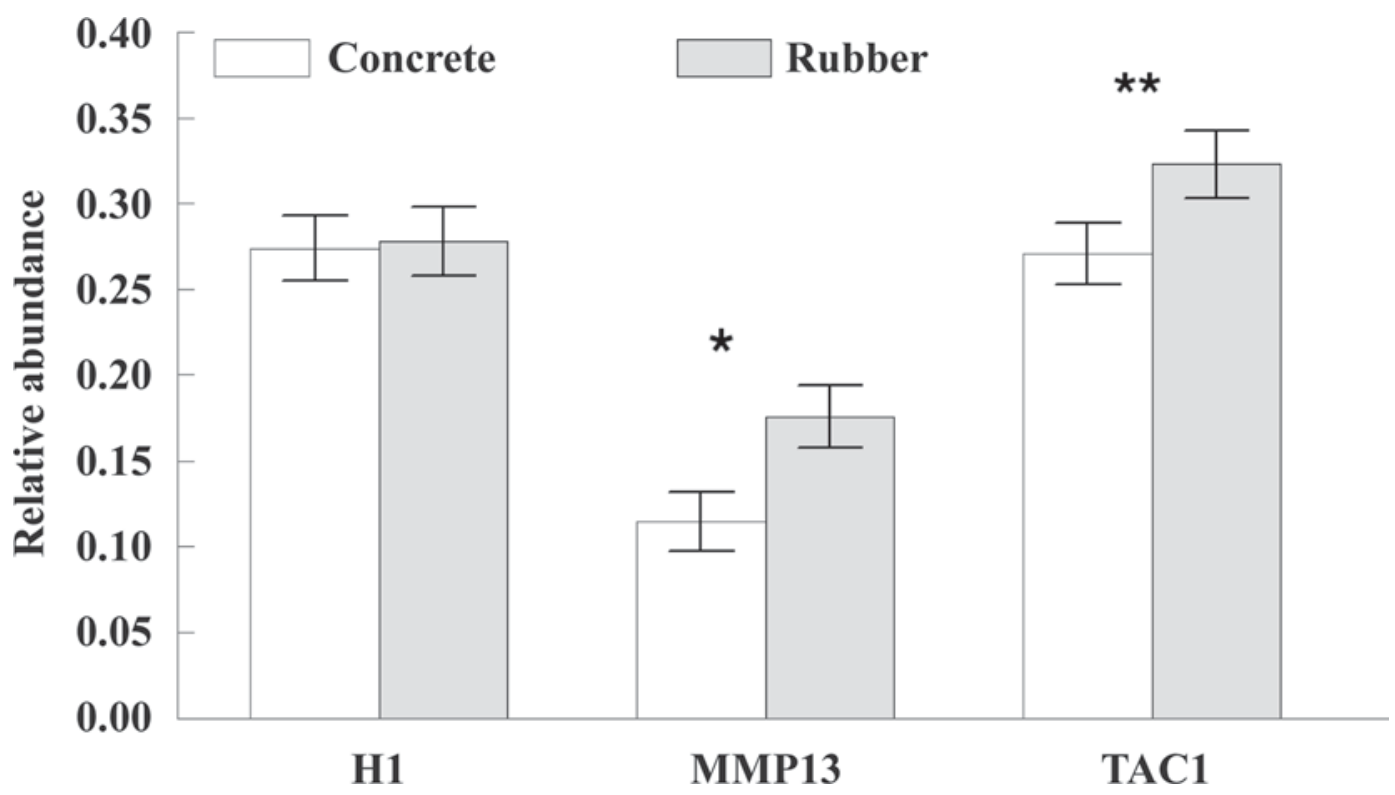

Figure 5. Relative expression of the 3 genes under investigation in cows on concrete (white bar) or rubber (gray bar) flooring. * and $* *$ indicate a difference at $P<0.02$ and $P<0.07$, respectively. $\mathrm{H} 1=$ histamine receptor 1 ; MMP13 = metalloproteinase 13 ; TAC1 $=$ tachikinin 1 .

the extra time standing was not confined to rubberfloored areas, but was also performed more in parts of the pen that were concrete, relative to similar areas in pens that had no rubber area. Platz et al. (2008) reported that cows on rubber floors walked almost twice the distance walked by cows on concrete and performed more grooming behaviors. Although these increases in behavior can be interpreted as indications of good animal welfare compared with cows on concrete, they could perhaps contribute to the potentially negative immune and molecular responses we observed in cows on rubber flooring. It is possible that although rubber flooring is softer than concrete flooring, the behavioral changes that it induces could slightly negatively affect cow immune status. Furthermore, increased activity and standing could explain the increased expression of genes associated with discomfort (TAC-1) and lameness (MMP-13). Previous studies have found no difference in inflammatory hoof lesion scores between cows on rubber or concrete (Vanegas et al., 2006; Boyle et al., 2007). The lack of difference in locomotion score in our study is in agreement with these studies. It is possible that differences in behavior that are associated with management on rubber or concrete flooring may be more likely to result in differential expression of these genes.

Although it is possible that the indications of stress that we detected in cows in the rubber treatment arose because of a long-term effect of rubber, these indications may also occur because of the short-term effect of leaving the softer rubber surface to go to the bedded pack.
It is possible that the move to straw flooring provided a greater relative improvement in comfort for cows that were moving from concrete to the bedded-pack compared with cows that were coming from rubber. However, although there were no differences between treatments at individual sampling points, expression of MMP-13 and TAC-1 mRNA was numerically greater in cows on rubber at drying off, which was at the end of an entire lactation after confinement on rubber flooring. This implies that the effects may be due to prolonged exposure to rubber. Furthermore, indications of differences in immune parameters between treatments were generally detected at calving and postpartum, which indicates that it may be the return to rubber flooring that stimulates a greater response than a return to concrete flooring.

However, it is important to note that in this study, none of the cows were clinically lame, and there was no overall difference in cow speed or locomotion score. It is possible that our results are applicable as a comparison between rubber and concrete flooring only when cows are not lame. Concrete flooring may have a negative effect on other measures of cow well being, such as increased propensity to develop hoof pathologies, or to have more severe hoof pathologies, as well as survivability within the herd. Indeed, Vanegas et al. (2006) found that although the odds of developing a claw lesion was similar for cows on rubber and concrete, odds of becoming lame over time and the proportion of cows requiring therapeutic hoof trimming was higher for cows on concrete. The initial sampling point oc- 

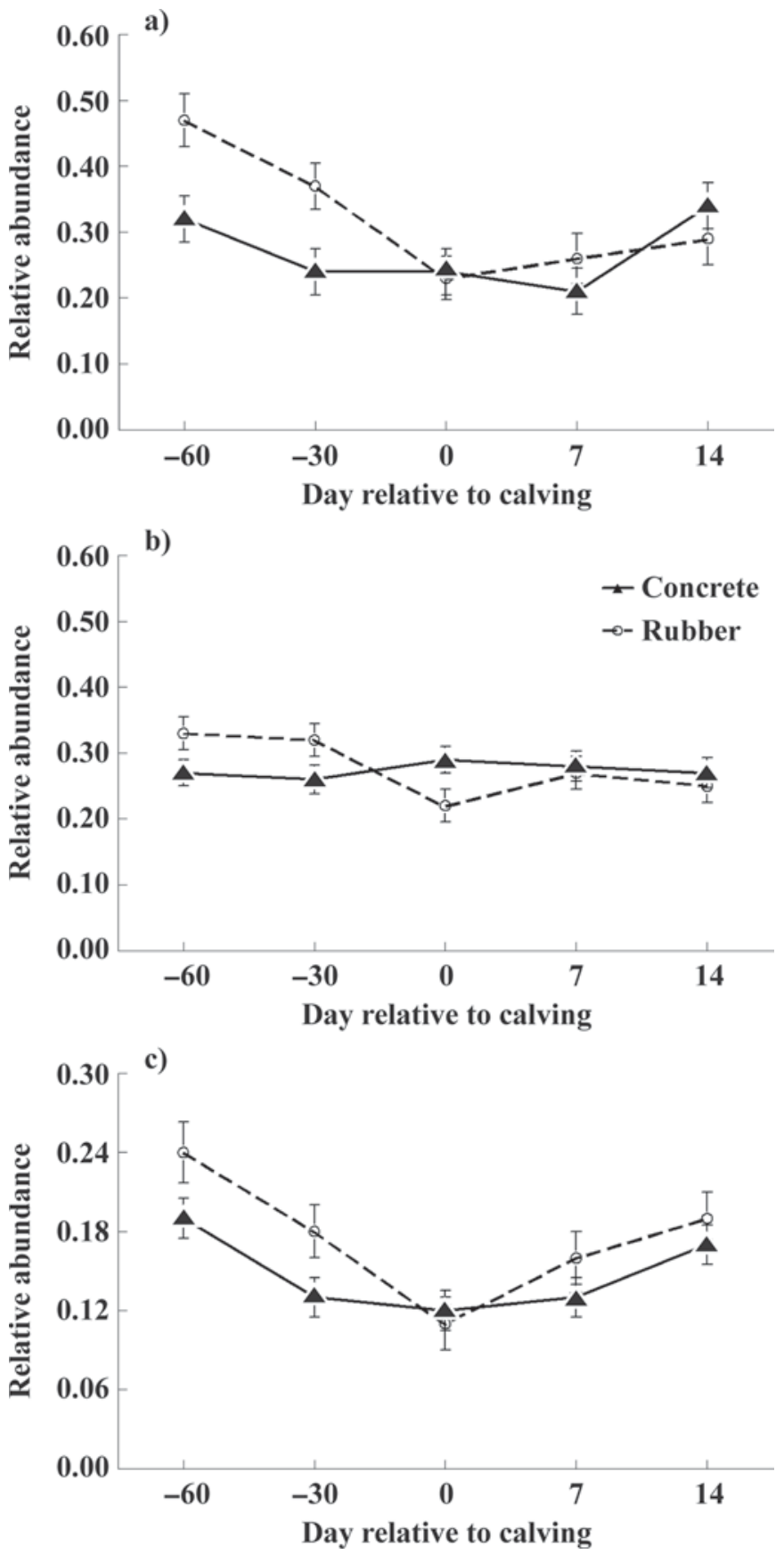

Figure 6. Relative expression of a) histamine receptor 1, b) tachikinin 1, and c) metalloproteinase $13 \mathrm{mRNA}$ isolated from blood polymorphonuclear cells in cows on concrete or rubber flooring at each sampling point.

curred at the end of the lactation, and it is possible that the high speed and locomotion scores recorded in the cows on concrete at this time may be because cows that became lame during the lactation were removed or culled. Immediately postpartum, it was the cows on rubber that displayed a slight improvement in locomotion, whereas cows on concrete did not. Our data were collected during a short time period, and thus further work is needed to elucidate more clearly the long-term effects on cow welfare of concrete and rubber flooring. It is possible that if we had continued to monitor cows until later in the lactation we would have seen more differences between treatments, in particular with regard to lameness, because of the propensity for cows to have more severe sole lesions 2 to 3 mo after calving. Moreover, by monitoring cows during the lactation it would also be possible to account for the confounding effect of removal of cows from either treatment due to lameness.

\section{REFERENCES}

Almeida, P. E., P. S. D. Weber, J. L. Burton, R. J. Tempelman, J. P. Steibel, and A. J. Zanella. 2007. Gene expression profiling of peripheral mononuclear cells in lame dairy cows with foot lesions. Vet. Immunol. Immunopathol. 120:234-245.

Bicalho, R. C., L. D. Warnick, and C. L. Guard. 2008. Strategies to analyze milk losses caused by diseases with potential incidence throughout the lactation: A lameness example. J. Dairy Sci. 91:2653-2661.

Blanco, M., I. Casasu, and J. Palacio. 2008. Effect of age at weaning on the physiological stress response and temperament of two beef cattle breeds. Animal 3:108-117.

Borderas, T. F., B. Pawluczuk, A. M. dePassille, and J. Rushen. 2004 Claw hardness of dairy cows: Relationship to water content and claw lesions. J. Dairy Sci. 87:2085-2093.

Boyle, L. A., J. F. Mee, and P. J. Kiernan. 2007. The effect of rubber versus concrete passageways in cubicle housing on claw health and reproduction of pluriparous dairy cows. Appl. Anim. Behav. Sci. 106:1-12.

Buckham-Sporer, K. R., L. Xiao, R. J. Tempelman, J. L. Burton, B. Earley, and M. A. Crowe. 2008. Transportation stress alters the circulating steroid environment and neutrophil gene expression in beef bulls. Vet. Immunol. Immunopathol. 121:300-320.

Burton, J. L., S. A. Madsen, L. C. Chang, P. S. D. Weber, K. R. Buckham, R. van Dorp, M. C. Hickey, and B. Earley. 2005. Gene expression signatures in neutrophils exposed to glucocorticoids: A new paradigm to help explain "neutrophil dysfunction" in parturient dairy cows. Vet. Immunol. Immunopathol. 105:197-219.

Clarkson, M. J., D. Y. Downham, W. B. Faull, J. W. Hughes, F. J. Manson, J. B. Merritt, R. D. Murray, W. B. Russell, J. E. Sutherst, and W. R. Ward. 1996. Incidence and prevalence of lameness in dairy cattle. Vet. Rec. 138:563-567.

Cook, N. B., T. B. Bennett, and K. V. Nordlund. 2005. Monitoring indices of cow comfort in free-stall-housed dairy herds. J. Dairy Sci. 88:3876-3885.

Cook, N. B., R. L. Mentink, T. B. Bennett, and K. Burgi. 2007. The effect of heat stress and lameness on time budgets of lactation dairy cows. J. Dairy Sci. 90:1674-1682.

Davis, A. K., D. L. Maney, and J. C. Maerz. 2008. The use of leukocyte profiles to measure stress in vertebrates: A review for ecologists. Funct. Ecol. doi:10.1111/j.1365-2435.2008.01467.x. In press.

de Grauw, J. C., C. H. A. van de Lest, R. van Weeren, H. Brommer, and P. A. J. Brama. 2006. Arthrogenic lameness of the fetlock: Synovial fluid markers of inflammation and cartilage turnover in relation to clinical joint pain. Equine Vet. J. 38:305-311.

Fell, L. R., I. G. Colditz, K. H. Walker, and D. L. Watson. 1999. Associations between temperament, performance and immune function in cattle entering a commercial feedlot. Aust. J. Exp. Agric. 39:795-802

Flower, F. C., and D. M. Weary. 2006. Effect of hoof pathologies on subjective assessments of dairy cow gait. J. Dairy Sci. 89:139146.

Fregonesi, J. A., C. B. Tucker, D. M. Weary, F. C. Flower, and T. Vittie. 2004. Effect of rubber flooring in front of the feed bunk on the time budgets of dairy cattle. J. Dairy Sci. 87:1203-1207. 
Goff, J. P. 2008. Immune suppression around the time of calving and the impact of metabolic disease. Hungarian Vet. J. 130:39-41.

Haufe, C. A., L. Gygax, B. Steiner, K. Friedli, M. Stauffacher, and B. Wechsler. 2008. Influence of floor type in the walking area of cubicle housing systems on the behaviour of dairy cows. Appl. Anim. Behav. Sci. 116:21-27.

Hernandez-Mendo, O., M. A. G. von Keyserlingk, D. M. Veira, and D. M. Weary. 2007. Effects of pasture on lameness in dairy cows. J. Dairy Sci. 90:1209-1214.

Kawabata, K., S. Nakai, M. Miwa, T. Sugiura, Y. Otsuka, T. Shinzato, Y. Hiki, I. Tomimatsu, Y. Ushida, F. Hosono, and K. Maeda. 2002. Changes in Mac-1 and CD14 expression on monocytes and serum soluble CD14 level during push/pull hemodiafiltration. Nephron 90:273-281.

Kulberg, S., A. K. Storset, B. Heringstad, and H. J. S. Larsen. 2002. Reduced levels of total leukocytes and neutrophils in Norwegian cattle selected for decreased mastitis incidence. J. Dairy Sci. 85:3470-3475.

O'Callaghan, K. A., P. J. Cripps, D. Y. Downham, and R. D. Murray 2003. Subjective and objective assessment of pain and discomfort due to lameness in dairy cattle. Anim. Welf. 12:605-610.

O'Driscoll, K., L. Boyle, P. French, and A. Hanlon. 2008. The effect of out-wintering pad design on hoof health and locomotion score of dairy cows. J. Dairy Sci. 91:544-553.

O'Driscoll, K., A. Hanlon, P. French, and L. Boyle. 2009. The effects of two out-wintering pad systems compared with free-stalls on dairy cow hoof and limb health. J. Dairy Res. 76:59-65.

Offer, J. E., D. McNulty, and D. N. Logue. 2000. Observations of lameness, hoof conformation and development of lesions in dairy cattle over four lactations. Vet. Rec. 147:105-109.

Parsons, S. L., S. A. Watson, P. D. Brown, H. M. Collins, and R. J. C. Steele. 1997. Matrix metalloproteinases. Br. J. Surg. 84:160166.

Platz, S., F. Ahrens, J. Bendel, H. H. D. Meyer, and M. H. Erhard. 2008. What happens with cow behavior when replacing concrete slatted floor by rubber coating: A case study. J. Dairy Sci. 91:999-1004

Radostits, O. M., C. C. Gay, K. W. Hinchcliff, and P. D. Constable 2007. Veterinary Medicine. Saunders-Elsevier, Philadelphia, PA.

Reber, A. J., D. C. Donovan, J. Gabbard, K. Galland, M. AcevesAvila, K. A. Holbert, L. Marshall, and D. J. Hurley. 2008. Transfer of maternal colostral leukocytes promotes development of the neonatal immune system I. Effects on monocyte lineage cells. Vet. Immunol. Immunopathol. 123:186-196.

Somers, J. G. C. J., K. Frankena, E. N. Noordhuizen-Stassen, and J. H. M. Metz. 2003. Prevalence of claw disorders in Dutch dairy cows exposed to several floor systems. J. Dairy Sci. 86:2082-2093.

Stefanowska, J., D. Swierstra, C. R. Braam, and M. M. W. B. Hendriks. 2001. Cow behaviour on a new grooved floor in comparison with a slatted floor, taking claw health and floor properties into account. Appl. Anim. Behav. Sci. 71:87-103.

Telezhenko, E., L. Lidfors, and C. Bergsten. 2007. Dairy cow preferences for soft or hard flooring when standing or walking. J. Dairy Sci. 90:3716-3724.

Troelstra, A., P. Antal-Szalmas, L. A. de Graaf-Miltenburg, A. J. Weersink, J. Verhoef, K. P. Van Kessel, and J. A. Van Strijp. 2007. Saturable CD14-dependent binding of fluorescein-labeled lipopolysaccharide to human monocytes. Infect. Immun. 65:22722277.

van der Tol, P. P. J., J. H. M. Metz, E. N. Noordhuizen-Stassen, W. Back, C. R. Braam, and W. A. Weijs. 2005. Frictional forces required for unrestrained locomotion in dairy cattle. J. Dairy Sci. $88: 615-624$.

Vanegas, J., M. Overton, S. L. Berry, and W. M. Sischo. 2006. Effect of rubber flooring on claw health in lactating dairy cows housed in free-stall barns. J. Dairy Sci. 89:4251-4258.

Webster, A. J. F. 2001. Effects of housing and two forage diets on the development of claw horn lesions in dairy cows at first calving and in first lactation. Vet. J. 162:56-65.

Wierenga, H. K., and H. Hopster. 1990. The significance of cubicles for the behaviour of dairy cows. Appl. Anim. Behav. Sci. 26:309337.

Williams, J. L., J. E. Minton, J. A. Patterson, J. Marchant Forde, and S. D. Eicher. 2008. Lairage during transport of eighteen-kilogram pigs has an impact on innate immunity and commensal bacteria diversity in the intestines. J. Anim. Sci. 86:1232-1244.

Yagi, Y., H. Shiono, Y. Chikayama, A. Ohnuma, I. Nakamura, and K.-I. Yayou. 2004. Transport stress increases somatic cell counts in milk, and enhances the migration capacity of peripheral blood neutrophils of dairy cows. J. Vet. Med. Sci. 66:381-387. 